\title{
Developing and implementing programmes for early detection, management and prevention of kidney and cardiovascular disease
}

\author{
Authors: Dr Ivor Katz, Sr Golebamanag Mdleleni, Sr Eugine Shezi, \\ Omar Butler, DrTrevor Gerntholtz
}

Dumisani Mzamane African Institute of Kidney Disease, Department of

Medicine, Chris Hani Baragwanath Hospital, University of the Witwatersrand

Address for correspondence:

Old Potch Road

Diepkloof

Soweto, South Africa

P O Box 92188

Norwood

Johannesburg

2117

Email:

bararenal@icon.co.za

The Research in the Institute is supported by the Bara Renal Fund which is a research fund managed by the Wits Foundation of the University of the Witwatersrand.

Support has been received by numerous donors.

Acknowledgments to Prof Sarala Naicker and Prof Helen Schneider.

ABSTRACT Chronic Kidney Disease (CKD) and Cardiovascular Disease (CVD) appear to be closely linked but also share common risk factors, making prevention, early detection and management for both diseases similar.

In 1998 CVD accounted for $30 \%$ of deaths worldwide and in South Africa for almost $40 \%$ in the same year. The number of these deaths due to underlying CKD remains unanswered, but it is clear that early detection and management of CKD through screening of patients at high risk, e.g. those with uncontrolled hypertension, diabetes and proteinuria or proteinuria alone, is an appropriate way to control this massive chronic disease burden. Added to this equation is the impact of HIV and/or proteinuria as a cause of CKD and CVD. Against a backdrop of poor control and management of chronic illnesses, there is a growing number of clinicians attempting to tackle this problem through the development of CVD and CKD prevention and early detection programmes.

Recognising the common risk factors makes it easier to plan and implement such programmes.

This article looks at an "Integrated Model" for managing chronic illnesses, which has been adopted internationally and locally. It discusses the experiences and challenges faced in attempting to implement programmes for CVD and CKD.

\section{INTRODUCTION}

There is a strong link between chronic kidney disease (CKD) and cardiovascular disease (CVD). They share common risk factors such as smoking, hypertension, diabetes, obesity and hyperlipidaemia, which are important causes of death in both developing and developed countries.
Patients with a reduced GFR are particularly prone to CVD, (1) and more likely to die of CVD before entering a dialysis or transplant programme.

To make matters worse, the burden of CVD is increasing.(2) CVD contributed $30 \%$ of all deaths in the world in 1998, most (78\%) occurring in low and middle-income countries. ${ }^{(3)}$ The global burdens of diabetes and CVD are set to rise by around 50\% and 150\% in the developed and the developing worlds respectively. It is estimated that by 2020 , in Africa alone, nearly 22.3 million people will be affected with diabetes, resulting in concomitant increases in the prevalence of chronic kidney disease (CKD) and end-stage renal disease (ESRD).(4) This means that more patients will die of strokes, heart failure and kidney failure, with the impact greatest in the developing countries like South Africa.

In under-resourced health systems, the focus has to move from expensive "end of the road" interventions such as dialysis, transplantation, cardiac catheterization and stenting to early intervention and primary prevention strategies by integrating care between specialists, primary care clinicians and the community. As CVD and CKD share similar risk factors, common preventative strategies may result in benefit for both. For instance, in Australia CKD requiring dialysis is almost epidemic among Australian Aboriginal people, and the Australian integrated Chronic Disease Outreach Programme (CDOP) $)^{(5)}$ was instituted to reduce the number of Aboriginal Australians starting dialysis in the Northern Territory. It was an integrative approach, which focused on detecting and treating common risk factors for CKD, namely hypertension, diabetes, and/or proteinuria. The programme substantially reduced the number of people needing dialysis and the all-cause mortality (Figure I).The latter was due predominantly to a reduction in CVD such as heart failure and stroke. In chronic illness treatment programmes most affected people have more than one morbidity justifying integrated, rather than disease specific programmes. ${ }^{(6)}$ It was uncommon in the Australian CDOP for a patient to have a single risk factor, i.e. CKD, hypertension or diabetes alone.

Unfortunately, as well as a large burden of non-communicable diseases (hypertension, diabetes) in developing countries, there is the additional problem of infectious diseases impacting on the increased prevalence 


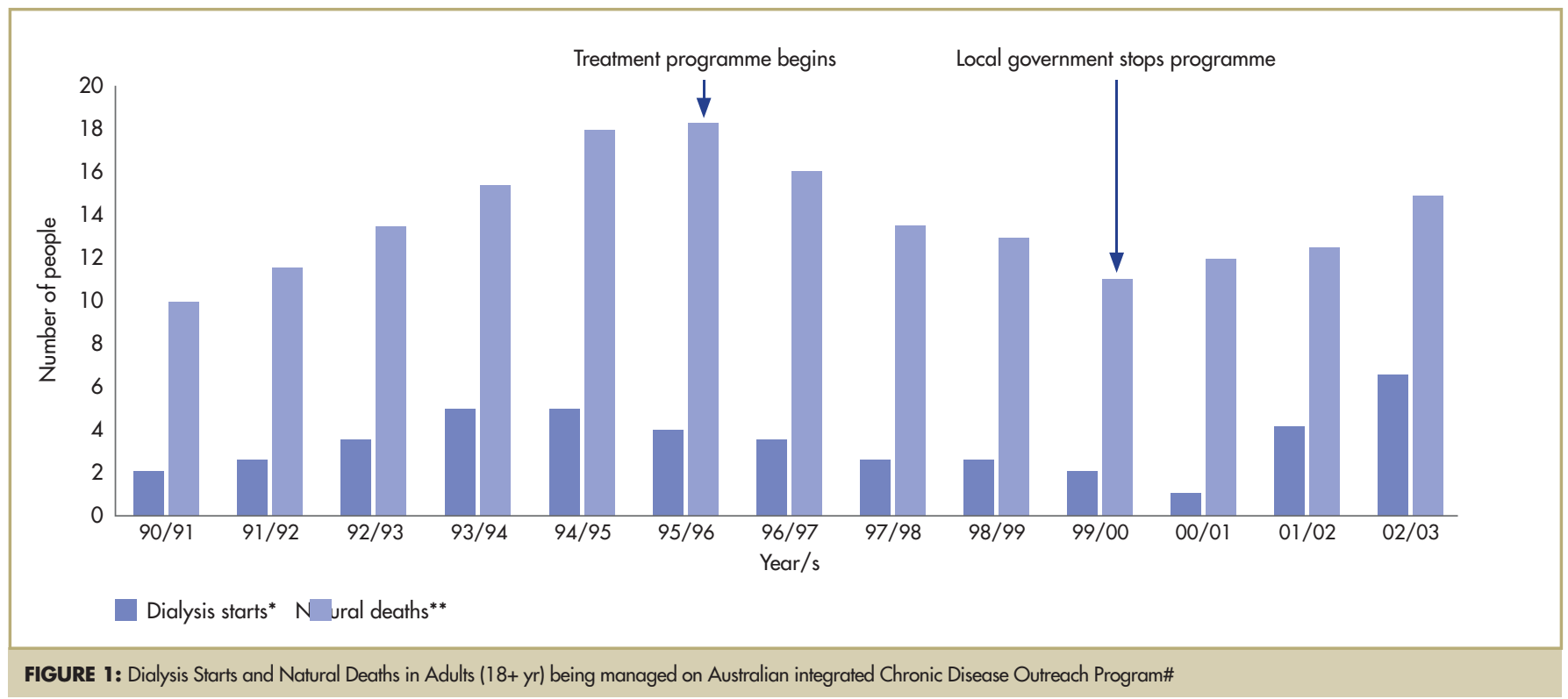

\#Annual Rolling Average, to mid 2003. *Dialysis starts = patients starting dialysis. ***Natural deaths = all-cause morbidity; main factors affecting all-cause mortality were strokes, heart failure and kidney failure. Hoy et al.(4)

of both CVD and CKD. HIV is obviously a special example of such an infectious disease whose impact has been greatly felt in both.

There is little information on HIV and CVD and CKD to inform planning of systematic chronic disease management programmes in the South African setting.

Non-communicable diseases (NCD) account for 37\% of all deaths in SA and HIV for a further 30\% (Figure 2).(7) The HIVIAIDS epidemic continues to grow at a rapid rate. The UNAIDS estimates that in 2000, $19.9 \%$ of adults were infected. Projections differ somewhat, but suggest

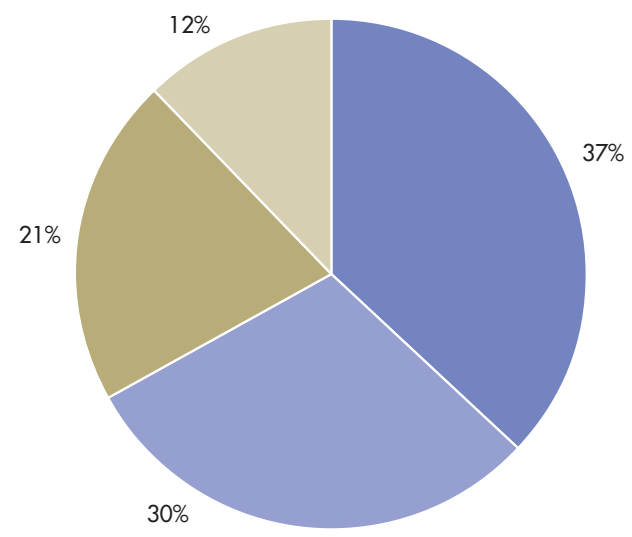

NCDs H /AIDS Povert, elated Injuries

FIGURE 2: Cause of death profile in South Africa from the SA Demographic Survey

SADHS 1998 Steyn et al.J Hypertension 2001. NCD = non-communicable diseases. that between 2000 and 2010, somewhere between 4-7 million people will die of AIDS. ${ }^{(8)}$ The estimated burden of renal deaths in HIV is unknown. HIV, when treated with anti-retroviral agents, can behave like a chronic disease. The combined impact of diseases like diabetes, hypertension and HIV will have a large impact on both CKD and CVD.

The KDOQ। guidelines have significantly improved our focus for detecting, following and managing patients with CKD. ${ }^{(9)}$ No reliable statistics for CKD exist for any African countries, including SA. In a chronic disease outreach programme (CDOP) running in Soweto, it was found amongst 619 patients being managed at primary care clinics with high risk diabetes (diabetes with hypertension or proteinuria) and uncontrolled hypertension that 9\% (54) had advanced kidney disease, i.e. GFR $<60 \mathrm{mls} / \mathrm{min}$ or significant proteinuria and some 4 patients (2\%) required immediate dialysis (Table I). ${ }^{(10)}$ Considering that only a small number of the 40000 patients being treated at these clinics were screened, the problem is larger than we would like to think.

TABLE I: Reasons for referral to a specialist from primary care level chronic disease outreach programme

\begin{tabular}{|l|c|c|}
\hline \multicolumn{1}{|c}{ Graduation } & Total(n) & Percent \\
\hline No graduation & 526 & 85 \\
\hline Stage3/4 CKD\# & 43 & 7 \\
\hline Stage 5 CKD \# & 4 & 1 \\
\hline Cardiac & 7 & 1 \\
\hline Proteinuria & 7 & 1 \\
\hline DM insulin & 7 & 1 \\
\hline Cholesterol* & 19 & 3 \\
\hline Died & 4 & 1 \\
\hline
\end{tabular}

\# CKD $=$ chronic kidney disease $*$ Cholesterol $=>7 \mathrm{mmol} / \mathrm{l}$ 
DEVELOPING AND

IMPLEMENTING

PROGRAMMES FOR

EARLY DETECTION

\section{RECOGNISING COMMON RISK FACTORS FOR PLANNING OF PREVENTION STRATEGIES}

We need to understand and grasp the burden of risk factors on chronic diseases in South Africa so that we can further recognize the need for a comprehensive early detection and prevention strategy.

The CVD burden and therefore, given the shared risk factor profile, the CKD burden in SA was evaluated to some extent in the South Africa Demographic and Health Survey (SADHS) in 1998. This national crosssectional survey is probably the most geographically representative survey to date. (II) A random sample of 13802 people, evaluated the prevalence and treatment status of hypertension in South Africans $\geq 15$ years old. The cut-off blood pressure levels used for analysis were 2160/95 $\mathrm{mmHg}$ but later analysis by Steyn included the more appropriate cut-off of $>140 / 90$. (7) The prevalence of hypertension was found to be $21 \%$ in both men and women, but the level of control was found to be worse in men compared with women (10\% and I8\%), and worse than the control in the NHANES III survey of $27 \%$. Just over $50 \%$ were aware of their diagnosis and less than 50\% were being treated. Thus, hypertension remains poorly diagnosed and managed in SA. In an unpublished review of chronic disease control in Soweto clinics, the control of hypertension and diabetes was dismal.(12) Only $8.4 \%$ of patients seen at the clinics had moderately acceptably control of blood pressure $(<\mid 40 / 90 \mathrm{mmHg})$ and this was similar for diabetes control $(<7 \%$ having blood glucose $<8 \mathrm{mmol} / \mathrm{L})$.

Diabetes mellitus is also a major problem and is conservatively estimated to occur in 4 million South Africans. ${ }^{(1)}$ Diabetic nephropathy remains a very important risk factor for CKD and CVD in SA. Incipient nephropathy is reported in $32 \%$ to $57 \%$ with a mean known duration of diabetes of 5- 10 years in a hospital based study. ${ }^{(13)}$ Overt proteinuria was reported in $5 \%$ to $28 \%$ and increased with duration of diabetes.

SADHS indicated that a further 4 million South Africans are suspected to have a further CVD and CKD risk, that of hyperlipidaemia.

SADHS also showed that $29 \%$ of females and $9 \%$ of males were obese $\left(\mathrm{BMI}>30 \mathrm{~kg} / \mathrm{m}^{2}\right.$ ), and $55 \%$ and $29 \%$ respectively were overweight $\left(\mathrm{BMI}>25 \mathrm{~kg} / \mathrm{m}^{2}\right)$. In the Pilot Soweto chronic disease outreach programme, the presence of major risk factors was extremely prominent (Table 2) and over $60 \%$ were obese by BMI and $43 \%$ by waist-hip ratios. (II) In the same population group 35\% had evidence of proteinuria. In a recent survey of 55 I people in the "normal population" in Soweto as part of the "Heart Awareness Day" programme, similar risk factor profiles were observed; $43 \%$ with a body mass index

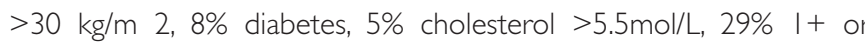
more microalbuminuria on single testing, 16\% smokers and 26\% with hypertension. It was also noted as many as $8 \%$ of people screened were unaware of their hypertension status (Figure 3).(14)

These studies highlight the existence of co-existing risk factors and comorbidities in chronic disease and "normal" populations. It also demonstrates the poor awareness and management of these risk factors and chronic diseases in those diagnosed with a problem, making

\begin{tabular}{|c|c|c|}
\hline \multirow[t]{2}{*}{ Parameters } & \multicolumn{2}{|c|}{ Patients screened } \\
\hline & $\mathrm{N}$ & $\#$ \\
\hline Age * & 625 & $57.5(11.9)$ \\
\hline Male & 645 & 201 (31.2\%) \\
\hline Diabetics * & 645 & $234(36.3 \%)$ \\
\hline Hypertensive * & 645 & $622(96.4 \%)$ \\
\hline Smokers * & 577 & $86(14.9 \%)$ \\
\hline Alcohol & 569 & $98(17.2)$ \\
\hline Waist, cm & 583 & $97.5(18.8)$ \\
\hline $\mathrm{BMl}, \mathrm{kg} / \mathrm{m} 2$ * & 581 & $32.7(8.6)$ \\
\hline Obese by WHR & 583 & $256(43.9 \%)$ \\
\hline $\mathrm{SBP} *$ & 619 & $153.0(21.6)$ \\
\hline DBP & 619 & $93.6(12.5)$ \\
\hline MAP & 619 & II3.4 (14.1) \\
\hline
\end{tabular}

\# Data are Mean (SD) or proportions

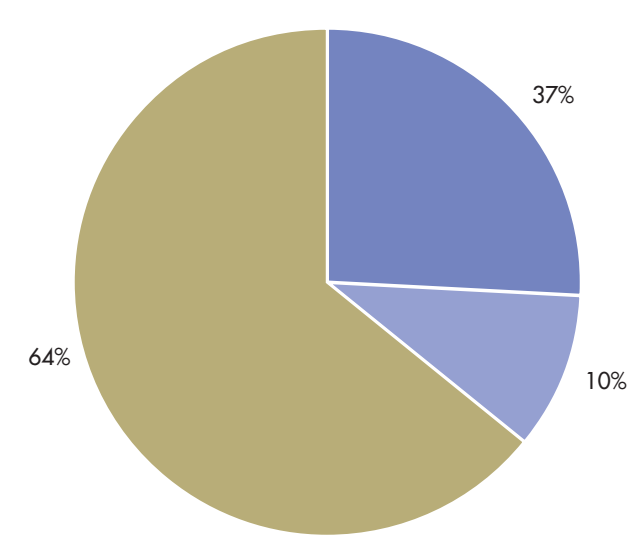

Known $\mathrm{HT}$ = people screened who were aware of their diagnosis or were being treated already for $\mathrm{HT}$

New HT = people unaware of their having hypertension at time of screening Normal $=$ people screened who had a blood pressure $<140 / 90 \mathrm{mmHg}$

FIGURE 3: Patients Screened in "Heart Awareness Day" in Soweto 
the argument for early detection of kidney and cardiovascular disease. The question remains how we should tackle this problem of CKD and CVD.

\section{EARLY DETECTION \& PREVENTION: AN INTEGRATED APPROACH}

A simple and integrated approach to risk factor and chronic disease management needs to be adopted. Lifestyle measures remain the key to the epidemic of NCD and HIV in the developing world. Public education and commitment to a healthy lifestyle, e.g. stop smoking, low salt diets, prudent eating plans, exercise and reducing high risk sexual behaviour, need to be emphasized.

The $\mathrm{WHO}$ recognizes the difficulty in achieving ideal circumstances and therefore advises those in the developing world to follow a more practical approach. The approach is modified according to one's capacity. ${ }^{(15)}$

A Chronic Disease Outreach Programme (CDOP) was initiated in 1999, in Soweto, a city of predominantly indigenous South African people. It is a melting pot of "transitional" people, moving from a traditional lifestyle to a predominantly unhealthy Westernized urban lifestyle.This community is also at high risk for chronic diseases, including HIV.(16) Against a known background of poor blood pressure and glucose control, the programme was implemented in 20 primary care clinics in Soweto and nearby regional clinics. The programme is developed around the Wagner Chronic Illness Care Model, which focuses on creating a prepared and proactive health team and an informed patient. ${ }^{(17)}$

This programme is based on an understanding that adequate blood pressure control, diabetic control and risk factor control will confer a specific effect (advantage) in preventing, reversing or retarding diabetes, hypertension and proteinuria, as well as those with established CKD and CVD. ${ }^{(16)}$ It also recognised the need for community support and integrating prevention strategies into the community through, for example, support groups for diabetic patients.

It focused on the key components of disease and treated, tracking and analyzing clinical outcomes. It also had a qualitative component, which served to assess the health delivery system, including health workers and patient compliance and satisfaction. In a recent study Landon et al. showed the value of evaluation in such public health initiatives. ${ }^{(18)}$ In this study they showed that integrated primary health care centers had considerably greater improvement in the composite measures of quality for the care of patients with chronic illnesses, asthma and diabetes. The focus in developing countries is also on high risk groups, recognizing the resource capabilities of these health services.

\section{PROGRAMME MODELS FOR CKD AND CVD DETECTION AND MANAGEMENT}

The Kidney Disease Outcomes Quality Initiative (KDOQI) Clinical Practice Guidelines for Chronic Kidney Disease draw on the results of NHANES III and the 1998 USRDS studies to establish the CKD stages. This staging protocol has significantly improved our focus for detecting, following and managing CKD. ${ }^{(9)}$ However, what this protocol exposed was the hierarchical or pyramid shape to kidney disease. It indicated that most CKD patients fall into CKD stages 2 or 3 . These are also the stages in which people are most likely to present with cardiovascular morbidity or mortality. So the options when establishing a prevention programme are to either screen an entire population, as in the Dutch PREVEND programme and the Australian Aboriginal CDOP studies or detect a cohort of people at the highest risk of disease (Figure 4). ${ }^{(19,20)}$ The approach in SA and other countries, like Australia, has been to focus more on the high risk population groups. ${ }^{(21,22)}$

We have a few options to consider before starting a programme. Firstly a prevention programme could be established on its own, with the

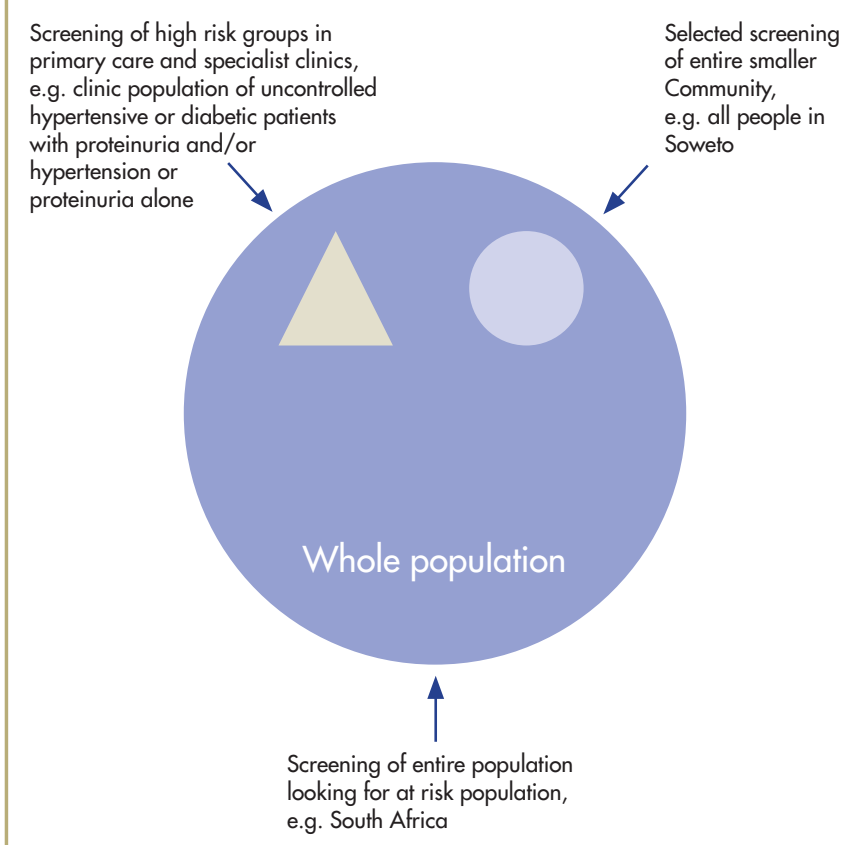

FIGURE 4: Potential approaches for early screening for detection and prevention of CKD and CVD and risk factors 
primary focus being the kidney or the heart as the organ to treat. The second option could be for the kidney or heart to fall under the gambit of all chronic illnesses, recognizing that managing the key chronic illnesses risk factors such as hypertension and diabetes will have the greatest impact on reducing the progression of kidney disease and cardiovascular disease. ${ }^{(23)}$ The broad range of kidney and heart problems and their etiologies makes the cardiologist or nephrologist well suited to follow an integrated approach to these chronic illnesses. ${ }^{(24)}$

\section{INTERNATIONAL MODELS FOR CVD AND CKD PREVENTION OR EARLY DETECTION}

Wendy Hoy's team state the programme in Australia is probably the most experienced in establishing kidney and cardiovascular protection programmes. They have helped develop programmes in Australian Aboriginal communities as well as other countries including India, Nigeria and South Africa. Key to this development is to engage community interest in chronic illness management and prevention strategies, to help assess needs in the community and to develop an agreement with the local community or health authority. ${ }^{(6)}$ Once these basic requirements have been met, then one can go on to help local staff implement the programme, and strive to ensure sustainability by providing the mechanisms or skills to evaluate processes and outcomes.

Other prevention CKD or CVD programmes or research programmes have also been established. An example of such an initiative is The Initiative for Cardiovascular Health Research in developing Countries (IC Health), an NGO that shares similar interests with the renal specialists. Their work is close to the coal face and they have funding from the World Bank and other partners, whose aims are to prioritize resource-sensitive research and to address the growing burden of cardiovascular diseases in the developing countries. They also prioritize research on sustainable models of disease prevention through primary health care in resource-poor settings. These model programmes deliver established safe and effective methods to reliably and affordably prevent cardiovascular disease. They acknowledge that, even though these methods of prevention are known, e.g. ACE inhibitors, management of risk factors, they still need to be delivered. They are therefore trying to develop large-scale cost-effective programmes in low and middleincome countries. The programmes have surveillance and intervention components. ${ }^{(25)}$ Other NGOs worldwide are also involved in similar prevention strategies, including Médecins Sans Frontières (MSF) and Global Forum for Health Research (GFHR). ${ }^{(26,27)}$

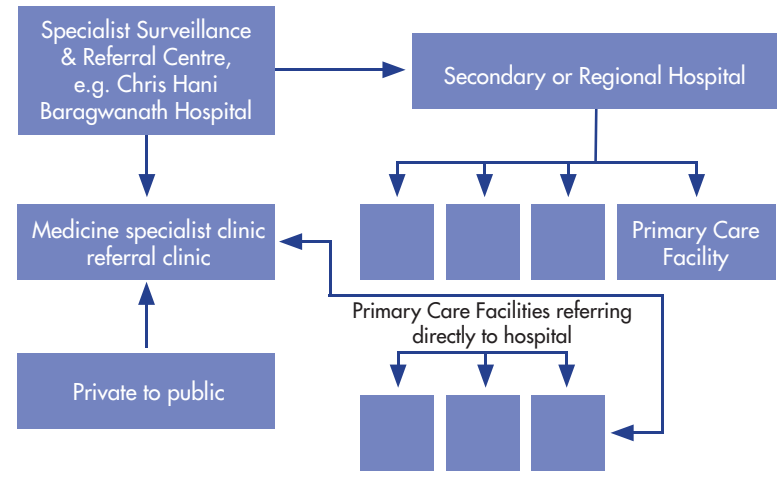

All centres are linked through CDOP, which acts as the clinical data Information capture centre.

FIGURE 5: An example of an early detection and prevention programme structure, using the Soweto CDOP structure as an example

\section{SOUTH AFRICAN INTEGRATED HEALTH CARE MODEL AND STRUCTURE}

In the CDOP programme described earlier, a tertiary hospital (Chris Hani Baragwanath) served as the focal point for decision support for primary care clinicians (PHCs), data collection (surveillance), data analysis and overall management of the programme (Figure 5). The CDOP "Functioning Unit" was established to fit into the cluster of primary, secondary and tertiary hospitals in a region. This model is the basis for public health primary care and tertiary models. It is also a model suitable for private health care. It recognizes that a single academic or tertiary hospital takes referrals from a region of health services, including primary health clinicians (family practitioners) and smaller hospitals, e.g. regional hospitals. The key component of this model is firstly recognizing which patients' diseases can be managed by a primary care centre, which just need advice (decision support) and which need referral (specialist management). In developing this model it is critical to understand what the PHCs and the existing resources can cope with, and when they should refer patients for specialised care. The "red"," "orange" and "green" traffic light approach was used to open or keep doors closed for referral. The programme defined red to mean that the door for referral was opened, e.g. GFR $<60 \mathrm{mls} / \mathrm{min}$ and multiple risk factors. An orange "light" was used to indicate the health worker should continue with caution and should observe the clinical problem until a further review in 6-I2 months, e.g. HbA I c not at target $<7 \%$. A specialist still provided regular decision support if required. When a green light was given, then the primary care clinician was permitted to continue with management and would screen again at a later date. 
This restructuring of the health system, as per the Wagner Model, allowed patients to be referred directly to a specialist clinic without being referred through a "casualty" (Figure 6). Patients would then arrive at the specialist centre with the appropriate investigations completed and a history of the patient's disease and progress already known. This resulted in improved efficiency in the management of the patient at the time of consultation. Once the patient was stabilized, they could be referred back to their primary clinic for ongoing care, unless disease was too advanced, e.g. GFR $>30 \mathrm{mls} / \mathrm{min}$. Such a patient would remain at the tertiary centres kidney disease remission and regression clinic and be prepared for dialysis or transplantation if necessary at a later stage.

Such initiatives could easily be adapted for the private health care sector.

\section{CHALLENGES WHEN ESTABLISHING DETECTION PROGRAMMES}

It is definitely possible to establish a chronic disease outreach programme in the developing world. There are some additional important fundamental issues to consider and remember when developing and implementing programmes for preventing kidney and cardiovascular disease. It is important to develop strong links with experts and to try and develop assistance when needed from local or international organizations that have had experience in prevention and early detection programmes. One has to ensure that, when managing chronic diseases in less developed countries, the establishment of an informed

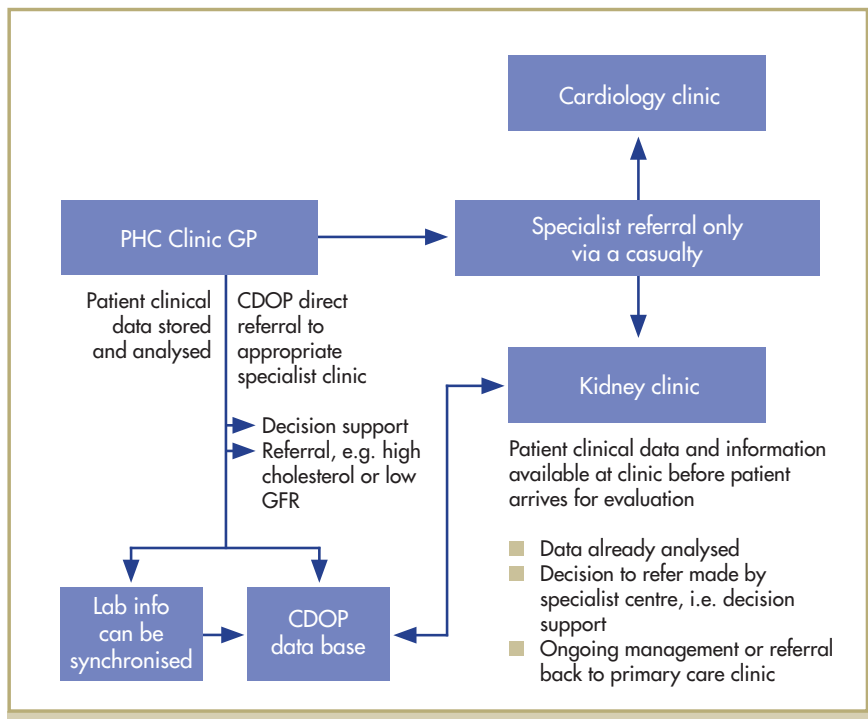

FIGURE 6: CDOP Model used for screening, early detection and referral of patients with advanced chronic kidney disease, or uncontrollable cardiovascular risk factors and proactive health team and strong patient and community partnerships are a priority. Establishing links and improved communication between primary, secondary and tertiary services takes ongoing joint planning and commitment. These components remain as important as adequate funding, although funding is an essential component. One has to focus not only on the technical aspects, but also on supporting and caring for staff. It is critical to recognise that good quality chronic disease management is best care delivered by a well functioning team, and does not rest on only the specialist or primary care clinician alone. ${ }^{(25)}$

The fundamental difficulties outlined in most prevention programmes are the staff shortages of local health workers and frequent absenteeism and attrition in clinics. These issues impact on health care more broadly. The causes are complex and deep-seated, but improved incentives for health workers, proper pay scales, empowerment, respect and good backup are all needed. High drop-out rates, up to $62 \%$ in both phases of the South African programme have occurred due to: I) staffing shortages; 2) inability of the nurses to fill in follow-up data when patients return; and 3) cutting of costs by the local regional health service. Continuity of care is a major problem in SA, with clinics seeing volumes of $3000-5000$ chronic disease patients per month and patient nurse ratios of 1:50 or 60. ${ }^{(28)}$ There are only two Nurse Coordinators following up patients in our CODP. Follow-up was thus dependent on local clinic support. All primary health care nurses were reluctant to be involved and nurses involved were not always available due to days off and having to rotate to other areas of the clinic (i.e. acute patient care, ARV programmes).

Ongoing challenges in SA include the lack of coordinator personnel at each site to facilitate the running and day-to-day management of the programme and especially the lack of insight and support from some senior department of health managers. Prevention strategies do not bring in immediate savings and cost efficiency, making prevention strategies less attractive. Early detection and good quality care may in fact result in an increase in initial cost for health care. The communication linkages include improved access to doctors at the tertiary/specialist care facility. Demands on time, compounded with the public health care system culture, remained a barrier to the programme's success in Soweto.

Despite shortages of staff and problems with running the programmes, the improvements in risk reduction, if sustained, should result in reduction in morbidity and mortality. This was glaringly obvious in the 
Australian Outreach Programme (Figure 1). Here the impact of the programme is clear, as is the lack of local government support for the programme, too.

There is a raised awareness for an integrated approach to management of chronic conditions. The WHO and initially Wagner have popularized similar models ${ }^{(24,29)}$ of integrated care. These models capture the complexity of providing health care for chronic conditions in an organized way. ${ }^{(24,28)}$

\section{CONCLUSIONS - INTEGRATED APPROACH TO CKD MANAGEMENT}

Novel methods of tackling the increased burden of CKD and CVD have to be established in the developing world if we are to tackle the daunting future burden facing our communities. We have to move from the "find and fix it" model of treating diseases to a more proactive integrated approach of tackling common risk factors, early detection of high risk patients, and then joint specialist and primary health care management. Health Care Funders (government and private medical aids) have to recognise the importance of prevention, early detection and comprehensive integrated strategies to managing CKD and CVD, and also have to be prepared to fund such initiatives. In treating the common diseases and risk factors like diabetes, hypertension, obesity, hyperlipidaemia and $\mathrm{HIV}$, we will ultimately be reducing the burden and morbidity of CKD and CVD in our communities. The examples and lessons learned in SA and in other countries where prevention programmes have been established could serve as a template as well as a stepping stone for other developing world and African communities.

\section{REFERENCES:}

I. Go A S. CGM, Fan D, McCulloch CE and Hsu C. Chronic Kidney Disease and the Risks of Death, Cardiovascular Events, and Hospitalization. N Engl J Med 2004;35 I ( 3 ) 1296-1305.

2. Murray CJL LA. (WHO). Global Burden of Diseases and Injuries. 1996.

3. WHO. (WHO). World Health Report 2002. 1999.

4. Schena FP. Epidemiology of end-stage renal disease: International comparisons of rena replacement therapy. Kidney Int. 2000;57(s74):39-45.

5. Hoy W E K-CS. (The University of Queensland). Final report on the Aboriginal Chronic Disease Outreach Program to the Office of Aboriginal and Torres Strait Islander Health and Kidney Health Australia. 2004 October.

6. Hoy WE SJ, McKendry K, Sharma S, Kondalsamy Chennakesavan S. Planning Services for noncommunicable chronic disease (NCDs) in Aboriginal communities. Abstract: ISN EDTA-ERA WCN Berlin; 2003.

7. Steyn K GT, Bradshaw D, Laubscher R, Fourie J. Hypertension in South African adults: results from the Demographic and Health Survey, 1998. I Hypertens. 2001:19(10):1717-25

8. Dorrington R BD, Bradshaw D, Laubscher R, Timaeus IM. (South African Medical Research Council). The impact of HIVIAIDS on adult mortality in South Africa. 2001 September 2001.

9. NKF-K/DOQI. NKF-K/DOQI clinical practice guidelines for chronic kidney diseases: evaluation, classification and stratification. Am J Kidney Dis. 2002:39:SI-S266.

10. Katz IJ SZ, Mdeleleni G, Butler O, Gerntholtz E. Evaluation of a chronic disease outreach programme in Soweto. University of the Witwatersrand; 2007.

II. Health Do. South Africa Demographic and Health Survey 1998. 1998.

12. Mohammed ES. (Gauteng Health Department). Gauteng Health Department Report on Hypertension and Diabetes control at Soweto Clinics. 2000 June 2000.

13. Kalk WJ Jj, Ntsepo S, et al. Ethnic differences in the clinical and laboratory associations with retinopathy in adult onset diabetes: studies in patients of African, European and Indian origins. I Intern Med. 1997;241:31-37.

14. Gerntholtz T Kl. Heart Awareness Screening Programme in Soweto. Dumisane Mzamane African Institute of Kidney Disease, Chris Hani Baragwanath Hospital, University of the Witwatersrand; 2006-2007.

15. Bonita R. Integrating NCD Surveillance into research on high blood pressure. In: Abstract, ed. Global Forum for Health Research 5. Arusha:WHO Non-communicable Diseases and Mental Health, Geneva; 2003.

16. Katz IJ LV, Butler O, Hopley M. An Early Evaluation of the Primary Prevention Programme (PPP), a Kidney Disease Renoprotection Programme (KDRP) in Soweto, South Africa. South African Renal Society Bi-annual Congress. Bloemfontein: Department of Rena Medicine, Chris Hani Baragwanath Hospital, University of the Witwatersrand, Soweto, South Africa.; 2002

17. EH Wagner CD. Improving Chronic Illness Care (ICIC). Vol. 2004. Seattle: The Robert Wood Johnson Foundation; 2004

18. Landon BE, Hicks LS, O'Malley AJ, Lieu TA, Keegan T, McNeil BJ aEG. Improving the Management of Chronic Disease at Community Health Centers. N Engl J Med 2007:356:921-34.

19. De Jong PE HH, Pinto-Sietsma SJ, de Zeeuw D. Screening for microalbuminuria in the general population: a tool to detect subjects at risk for progressive renal failure in an early phase? Nephrol Dial Transplant. 2003; I 8: I0-13.

20. Hoy WEWZ, Baker PR, Kelley AM. Reduction in natural death and renal failure from a systematic screening and treatment programme in an Australian Aboriginal community. Kidney Int. 2003;63(s83):s66-s73.

21. Hoy W E K-CS, Scheppingen-Smith J, Sharma S and Katz I. A chronic disease outreach program for Aboriginal communities. Kidney Int. 2005;68(S98):S76-S82.

22. Katz IJ SE, Mdleleni G, Butler OM, Gerntholtz TE, Mabubula E, Magagane LP, Naicker S, Schneider $\mathrm{H}$. Detecting chronic kidney disease (CKD) - 5-year experience of the Chronic Disease Outreach Primary Prevention Programme (CDOPPP) in Soweto. In: C. S, ed. South African Renal Society Congress. Cape Town; 2006.

23. Katz I. International aid and medical practice in the less-developed world: Doing it right, what can renal organizations learn? Kidney Int. 2005;68(S98):S60-S65.

24. Epping-Jordan JE. Integrated approaches to prevention and control of chronic conditions. Kidney Int. 2005;98(S98):S86-88.

25. Katz IJ. International Aid and the Formation of Successful Chronic Kidney Disease Prevention Programs. I ed. Vol. I New York: Marcel Dekker; 2005. (Nahas Me, ed. Nephrology in the developing world.)

26. MSF MSF. The MSF role in emergency medical aid.Vol. 2004; 2004.

27. GlobalForumHR. Global Forum for Health Research http://www.globalforumhealth org/pages/index.asp. Vol. 2004. Geneva: Global Forum for Health Research; 2004.

28. Katz IJ HW, Kondalsamy-Chennakesavan S, Gerntholtz T, Scheppingen J, Sharma S, Butler O, Shezi E, Mdleleni G, Mthombeni D. . Chronic kidney disease management - what can we learn from South African and Australian efforts? Blood Purif. 2006:24(1): I I5-22.

29. Wagner E. Meeting the needs of chronically ill people. BMI. 200 I:323:945-946. 